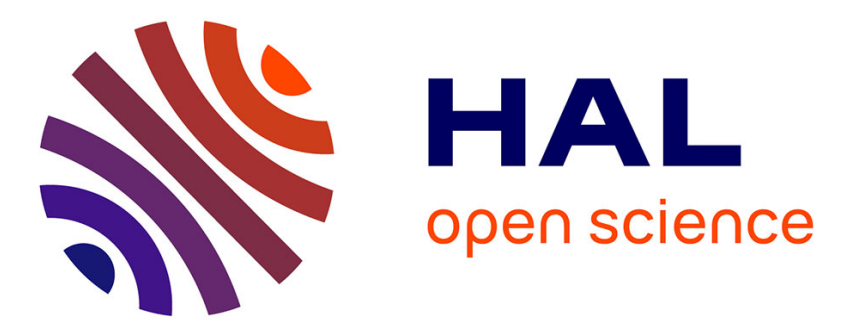

\title{
Multi-objective methodology to find the optimal forward current to supply Light Emitting Diode (LED) lightings
}

Jérémy Dulout, Angel Barroso, Lionel Séguier, Bruno Jammes, Pascal Dupuis, Georges Zissis, Corinne Alonso

\section{- To cite this version:}

Jérémy Dulout, Angel Barroso, Lionel Séguier, Bruno Jammes, Pascal Dupuis, et al.. Multi-objective methodology to find the optimal forward current to supply Light Emitting Diode (LED) lightings. 51st Industry Applications Industry (IAS) Annual Meeting (IAS 2016), Oct 2016, Portland, OR, United States. 10.1109/IAS.2016.7731899 . hal-01356352

\section{HAL Id: hal-01356352 https://hal.science/hal-01356352}

Submitted on 25 Aug 2016

HAL is a multi-disciplinary open access archive for the deposit and dissemination of scientific research documents, whether they are published or not. The documents may come from teaching and research institutions in France or abroad, or from public or private research centers.
L'archive ouverte pluridisciplinaire HAL, est destinée au dépôt et à la diffusion de documents scientifiques de niveau recherche, publiés ou non, émanant des établissements d'enseignement et de recherche français ou étrangers, des laboratoires publics ou privés. 


\title{
Multi-objective methodology to find the optimal forward current to supply Light Emitting Diode (LED) lightings
}

\author{
Jérémy Dulout ${ }^{1}$, Angel Barroso ${ }^{1,2}$, Lionel Séguier ${ }^{1}$, Bruno Jammes ${ }^{1}$, Pascal Dupuis ${ }^{2}$, \\ Georges Zissis ${ }^{2}$, Corinne Alonso ${ }^{1}$ \\ ${ }^{1}$ LAAS-CNRS, Université de Toulouse, CNRS, UPS, France \\ ${ }^{2}$ LAPLACE, Université de Toulouse, CNRS, UPS, France \\ Email: jdulout@laas.fr, alonsoc@laas.fr
}

\begin{abstract}
Light emitting diodes (LEDs) are commonly expected to be the future of lighting because of a high luminous efficacy, a long lifetime and a high color rendering index (CRI). Nevertheless, the performance and the reliability of an LED are strongly dependent on the LED junction temperature. This paper presents a multi-objective methodology to find the optimal forward current subject to the annualized cost of the luminaire (initial capital cost, replacement cost, operation and maintenance cost...) and the annualized energy consumption. A simple LED model based on empirical data has been developed and takes into account optical, electrical, thermal and ageing behaviour. Three different white LEDs have been evaluated through several combinations of forward currents and heatsinks to satisfy a given mission profile. A set of optimal solutions has been determined by Pareto optimization.
\end{abstract}

Keywords - Life estimation, Light emitting diodes (LED), Light sources, Pareto optimization, system analysis and design, thermal modeling.

\section{INTRODUCTION}

Nowadays, the world is illuminated by more than 33 billion artificial sources. In 2005, the consumption of grid-based electric lighting was around $2650 \mathrm{TWh}$, about $19 \%$ of the total electricity consumption [1]. To reduce the increasing demand of electricity [2], the use of LED lamps with high electricity to light conversion efficiency is a promising solution. Indeed, the average efficiency is around 35\% for LEDs, far better than the incandescent light bulbs with $5 \%$ and the fluorescent lamps with $20 \%$ [3]. The question of environmental impacts, even if it is a real issue, is not discussed in this paper. For more information on this subject, please refer to the article published by the U.S. department of energy (DOE) on the life cycle assessment (LCA) of incandescent, compact fluorescent, and LED lamps [4]. In this report, LED lamps appear to be the best solution in terms of life cycle energy consumption and were expected to be nearly twice better in a couple of years.

However, a complete manufactured LED lamp is still expensive and special care must be taken with light output and ageing that can be significantly affected by the operating temperature $[5,6]$. Recent studies have reported the relationships between photometric, electrical and thermal aspects for LED systems [7-10].
To avoid thermal runaway, this type of lighting is powered by a power converter, also called LED driver, commonly running in continuous conduction mode (CCM) and regulated by a single current control loop, as in the example described in [11]. Other more complex control schemes have also been designed to use accurately and efficiently LED lamps [12, 13]. The control is crucial to ensure LED good performances since current waveform has photometrical and colorimetrical impacts on light emission [14]. Moreover, it also enables to avoid potential health issues inherited from LED flickering [15-17].

In this study, two criteria in conflict with each other must be satisfied simultaneously to find the optimal LED current: the cost of the luminaire and the energy consumption, both over 20 years. To solve this problem, a Pareto multi-objective optimization is proposed. Many systems are faced to the same problem, even with far more objectives to satisfy, especially in renewable power systems [18]. A recent paper presents the state of art of meta-heuristics methods used to solve multiobjective problems [19].

This paper is organized as follows: section II introduces the LED string specifications and the optimization method. In section III, the LED string combination and the study of LED luminous efficacy is presented and assessed for three different white LEDs. Section IV details the thermal model of an LED, while the ageing model of an LED is described in section V. The cost of an LED luminaire with heatsinks and the results of the proposed method are discussed in section VI.

\section{OPTIMIZATION METHODOLOGY}

In order to obtain a good quality of illumination, it has been chosen to control the current supplied in each LED of the luminaire. As LEDs have not exactly the same V-I characteristics, a simple configuration is to associate LEDs in a single string but it creates a reliability concern: if a LED fails as open circuit, the entire luminaire will be failed. A study [20] presents the different possible associations (single string, series string or series-parallel string) and a method to achieve current equalization. 
The goal of our study is to evaluate a $3600 \mathrm{~lm}$ luminaire which corresponds to a common standard lighting device constituted by 3 fluorescent $-1200 \mathrm{~lm}$ tubes of $14 \mathrm{~W}$.

To evaluate the behaviour of the LED luminaire, different forward currents will be computed and a mission profile close to a typical shopping center lighting profile has been chosen, as described in Fig 1.

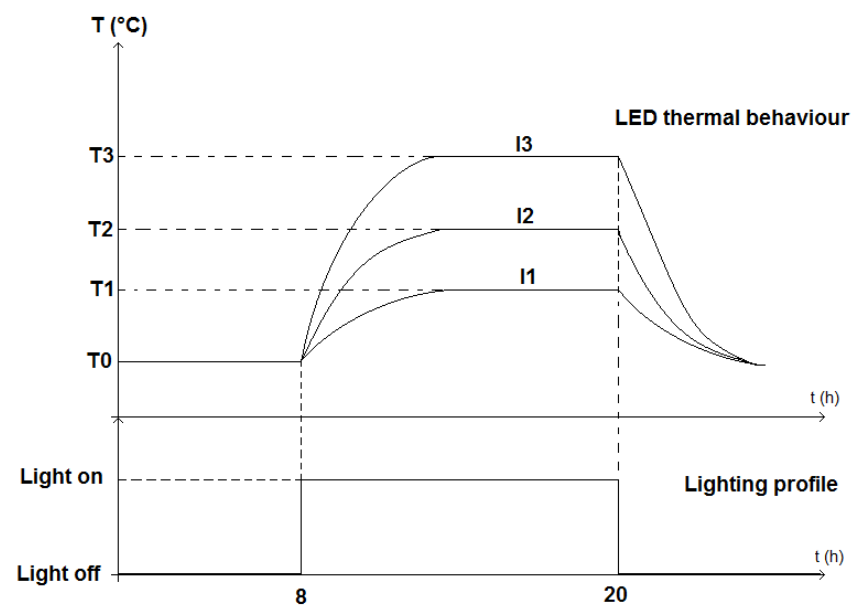

Fig. 1. Typical shopping center lighting profile

A Pareto optimization will be used to find forward currents making the best trade-offs between the annualized cost of the luminaire and the annualized energy consumption over 20 years. This method is used in many disciplines to find optimal solutions when objectives are conflicting. It is not convenient to deal with the price of energy because it varies from a state to an other, depending on the season, governmental rules... In our case, the main advantage of the Pareto method is to avoid the use of the price of energy, an arbitrary weighting coefficient, to compare the cost of the luminaire and the energy consumption. In multi-objective optimization, optimal solution is not unique, a set of non-dominated solutions is given and it forms the so-called Pareto front. Then, an expert will choose one solution among non-dominated solutions, regarding to his experience and convenience.

In an iterative and incremental way, all forward currents and LED combinations are simulated by using the LED model which will be developed in the next sections. In our case, currents from $50 \mathrm{~mA}$ to $700 \mathrm{~mA}$ will be evaluated. Currents below 50mA will not be computed because it implies a luminaire with a very large number of LEDs. Because the junction temperature of the LED will be too high and could damage the LEDs, currents above $700 \mathrm{~mA}$ will not be computed too. A flowchart of the proposed method is illustrated in Fig. 2.

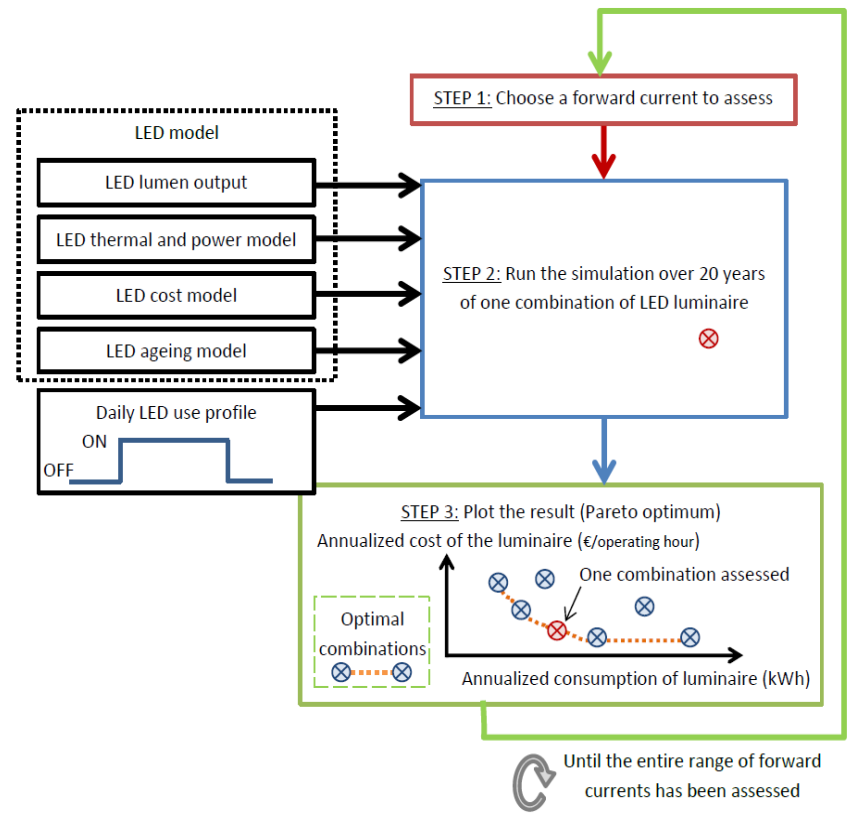

Fig. 2. Flowchart of the LED optimization methodology

Three different types of white LEDs with similar properties have been used for experiments. Main characteristics are gathered in Table I [21-23].

TABLE I

DATA FROM MANUFACTURERS OF LEDS USED FOR EXPERIMENTS

\begin{tabular}{c|c|c|c}
\hline & $\begin{array}{l}\text { Cree } \\
\text { XTEAWT } \\
\text { GE5 }\end{array}$ & $\begin{array}{l}\text { Lumileds } \\
\text { LUXEON } \\
\text { Rebel plus } \\
\text { LX18- } \\
\text { P140-3 }\end{array}$ & $\begin{array}{l}\text { OSRAM } \\
\text { OSLON } \\
\text { square } \\
\text { 5L7N-1 }\end{array}$ \\
\hline Viewing angle $\left({ }^{\circ}\right)$ & 115 & 120 & 120 \\
\hline $\begin{array}{c}\text { Luminous flux }(1 \mathrm{~lm}) \text { at } \\
85^{\circ} \mathrm{C} \text { junction temp. }\end{array}$ & 130 & 103 & 194 \\
@ 350mA & $@ 350 \mathrm{~mA}$ & $@ 700 \mathrm{~mA}$ \\
\hline Forward voltage $(\mathrm{V})$ & 3.4 & 2.85 & 2.85 \\
\hline Max. junction temp. $\left({ }^{\circ} \mathrm{C}\right)$ & 150 & 150 & 150 \\
\hline $\begin{array}{c}\text { Max. thermal resistance } \\
\text { junction/solder point } \\
\left({ }^{\circ} \mathrm{C} / \mathrm{W}\right)\end{array}$ & 5 & 9 & 3.9 \\
\hline Price $(€)$ & 1.36 & 1.36 & 2.38 \\
\hline
\end{tabular}

Experimental tests have been done with LEDs soldered on an aluminum printed circuit board (PCB). For each type of LEDs, three LEDs have been associated in series and the results have been averaged. A heatsink with a thermal resistance of $1.2 \mathrm{~K} / \mathrm{W}$ has been added and silicone thermal grease with a conductivity of $0.9 \mathrm{~W} / \mathrm{mK}$ makes a good thermal conduction between the PCB and the heatsink.

In order to evaluate the thermal behaviour of an LED, a battery cycler BioLogic BCS-815 and temperature chamber ESPEC SU-221 have been used, Fig. 3. 


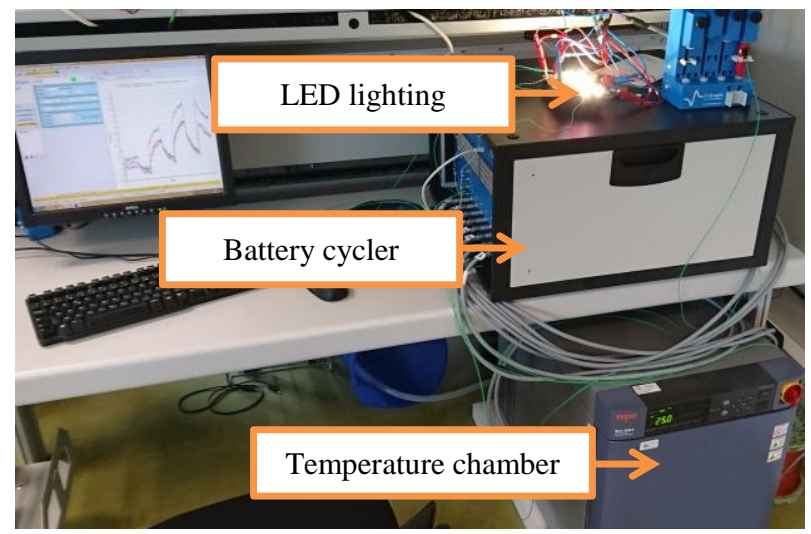

Fig. 3. Experimental setup assessing LEDs

\section{LED LUMINOUS FLUX}

To determine the number of LEDs that are needed to obtain the desired luminous flux, the luminous efficacy has been assessed with a sourcemeter Keithley 2602A, an integrating sphere and a spectrometer Specbos 1201 in a controlled temperature room $\left(22^{\circ} \mathrm{C}\right)$. All measures have been done after 40 minutes to ensure that LEDs are thermally stabilized. The LED junction temperature is estimated, based on measurements of a thermocouple placed as close to the LED as possible. Further explanations about thermal aspects will be given in the next section. Optical experimental results are shown in Fig 4.

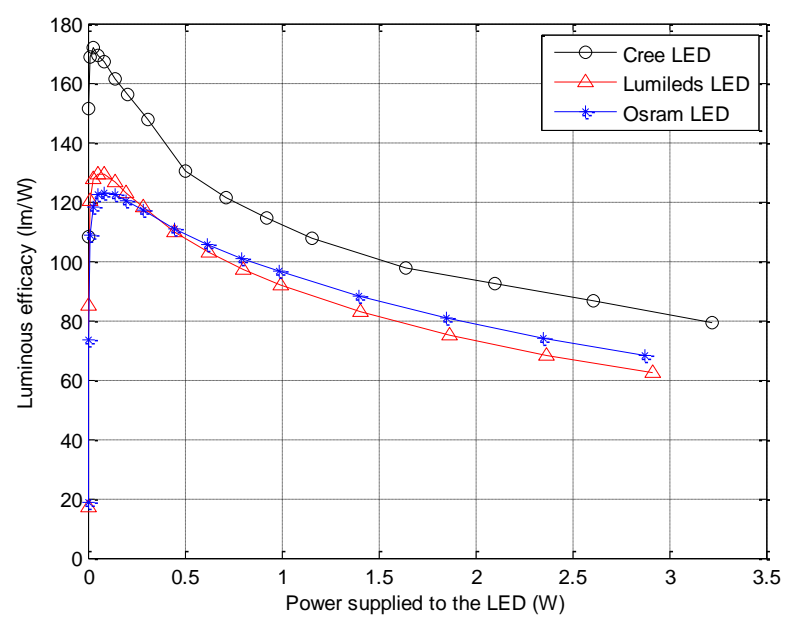

Fig. 4. Luminous efficacy vs. Power for the three tested LEDs

It can be noted that the forward current used to supply an LED has a strong impact on the luminous efficacy. In Fig. 4, for each type of LED, currents between $50 \mathrm{~mA}$ and $100 \mathrm{~mA}$ lead to the best luminous efficacy.

The number of LEDs noted $\mathrm{N}_{L E D}$ required to have the $36001 \mathrm{~m}$ desired luminous flux, as previously stated, for a given supplied power $\mathrm{P}_{\text {Led }}$, can be calculated:

$$
\mathrm{N}_{L E D}\left(\mathrm{P}_{\text {Led }}\right)=\frac{\mathrm{LF}_{d}}{\eta_{\text {Lum }}\left(\mathrm{P}_{\text {Led }}\right) \times \mathrm{P}_{\text {Led }}}
$$

where $\mathrm{LF}_{d}$ is the desired luminous flux, $\eta_{\text {Lum }}\left(\mathrm{P}_{\text {Led }}\right)$ is the luminous efficiency obtained for a given supplied power noted $\mathrm{P}_{\text {Led }}$.

Obviously, the power of an LED luminaire is defined as:

$$
\mathrm{P}_{\text {Lum }}=\mathrm{N}_{\text {LED }} \times \mathrm{P}_{\text {Led }}
$$

For each forward current, a LED string combination is calculated based on equations (1) and (2). In the actual context of low consumption electric appliances, the consumption of the LED luminaire has to be taken into account. The different combinations are plotted in Fig. 5. As stated before, forward currents below $50 \mathrm{~mA}$ have been removed from this plot because thousands LEDs were necessary to obtain a luminous flux of $3600 \mathrm{~lm}$.

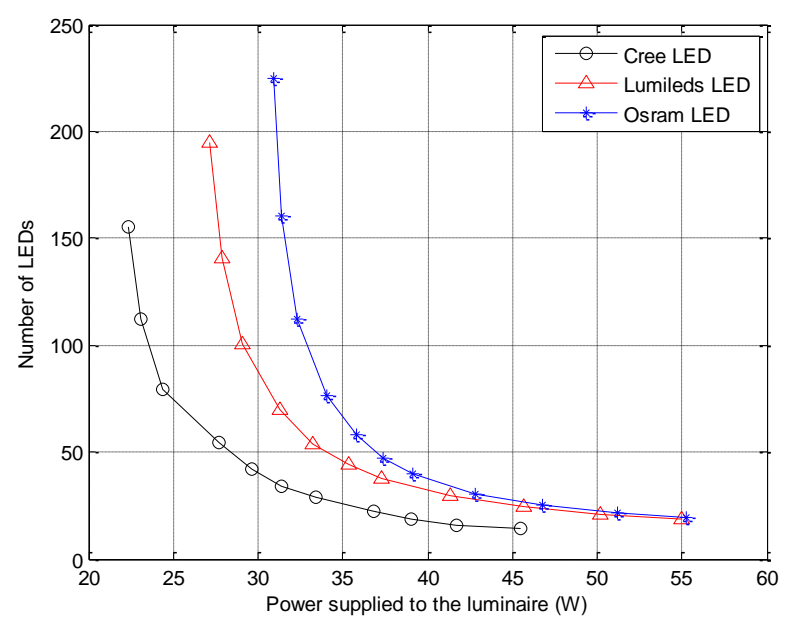

Fig. 5. Luminous efficacy vs. Power for the three tested LEDs

The next section is focused on the influence of the forward current on the junction temperature of the LED. Indeed, the junction temperature affects the luminous flux and lifetime of an LED [5-9].

\section{THERMAL MODELING OF AN LED}

As any P-N junction, the junction temperature of an LED is heating when supplied. Many models are available to accurately represent the thermal behavior of an LED such as the Shockley equation [24-25]. In this paper, a simplified steady state thermal model is derived from [7]. The variables of this model are represented in Fig. 6.

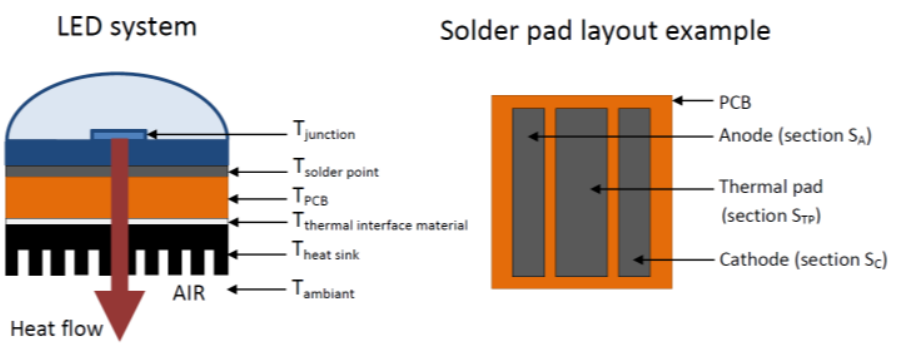

Fig. 6. Thermal variables used to model an LED system 
An LED luminaire can be modeled with a simple resistor network to define a static thermal model as illustrated in Fig. 7.

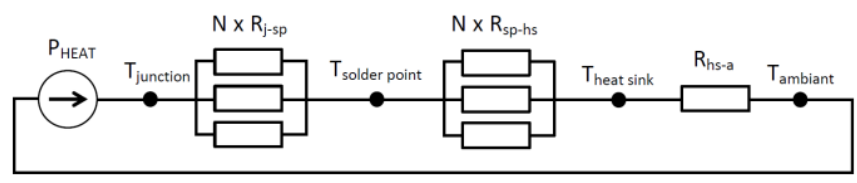

Fig. 7. Thermal model of an LED

The junction temperature is difficult to measure and can be estimated by using a thermocouple placed as close as possible to the LED. The temperature measured by this thermocouple is called the solder point temperature.

Based on the static thermal model presented in Fig. 7, the temperature of the solder point can be predicted for each forward current. Thus, if $\mathrm{N}_{L E D}$ LEDs are mounted on the same heatsink, the temperature of the solder point can be computed with the following relation derived from Fourier's law of heat conduction:

$$
\mathrm{T}_{s p}=\mathrm{T}_{a}+\left(\frac{1}{\mathrm{~N}_{L E D}} \mathrm{R}_{s p-h s}+\mathrm{R}_{h s-a}\right) \mathrm{P}_{h e a t}
$$

where

$\mathrm{T}_{s p}$ is the temperature of the solder point $\left({ }^{\circ} \mathrm{C}\right)$

$\mathrm{T}_{a}$ is the ambient temperature $\left({ }^{\circ} \mathrm{C}\right)$

$\mathrm{N}_{L E D}$ is the number of LEDs mounted on the same heatsink.

$\mathrm{R}_{s p-h s}$ is the thermal resistance between the solder point and the heatsink $\left({ }^{\circ} \mathrm{C} / \mathrm{W}\right)$

$\mathrm{R}_{h s-a}$ is the thermal resistance between the heatsink and ambient $\left({ }^{\circ} \mathrm{C} / \mathrm{W}\right)$

$\mathrm{P}_{\text {heat }}$ is the amount of input power converted by the LED as heat $(\mathrm{W})$

$\mathrm{P}_{\text {heat }}$ is calculated as follows:

$$
\mathrm{P}_{\text {heat }}=\eta_{\text {heat }} \mathrm{N}_{L E D} \mathrm{~V}_{f} \mathrm{I}_{f}
$$

with

$\eta_{\text {heat }}$ the non-efficiency of an LED, it describes the amount of heat converted from input power. As described in [26], $\eta_{\text {heat }}=0.85$ is considered

$\mathrm{V}_{f}$ and $\mathrm{I}_{f}$ are respectively the forward voltage $(\mathrm{V})$ and the forward current (A) of a single LED.

Thermal conductivity is generally used to define any PCB and thermal grease. $\mathrm{R}_{s p-h s}$ corresponds to the sum of PCB and thermal grease thermal resistances. Here is the relation between the thermal resistance $\mathrm{R}_{x}$ of a material and its thermal conductivity:

$$
\mathrm{R}_{x}=\frac{\mathrm{L}}{k A}
$$

with

L the thickness of the material $x(\mathrm{~mm})$

$\mathrm{k}$ the conductivity of the material $x(\mathrm{~W} / \mathrm{mK})$

A the contact area between the heating device and the material $x\left(\mathrm{~mm}^{2}\right)$

As previously mentioned, three strings of LEDs will be evaluated. Each string is constituted by three identical LEDs. LED strings have been powered separately in a $25^{\circ} \mathrm{C}$ temperature chamber with current pulses of 30 minutes from $50 \mathrm{~mA}$ to $700 \mathrm{~mA}$ with $50 \mathrm{~mA}$ increments. Rests of 30 minutes have been done between two pulses. In Fig. 8, the voltage of the string has been averaged to a single LED.

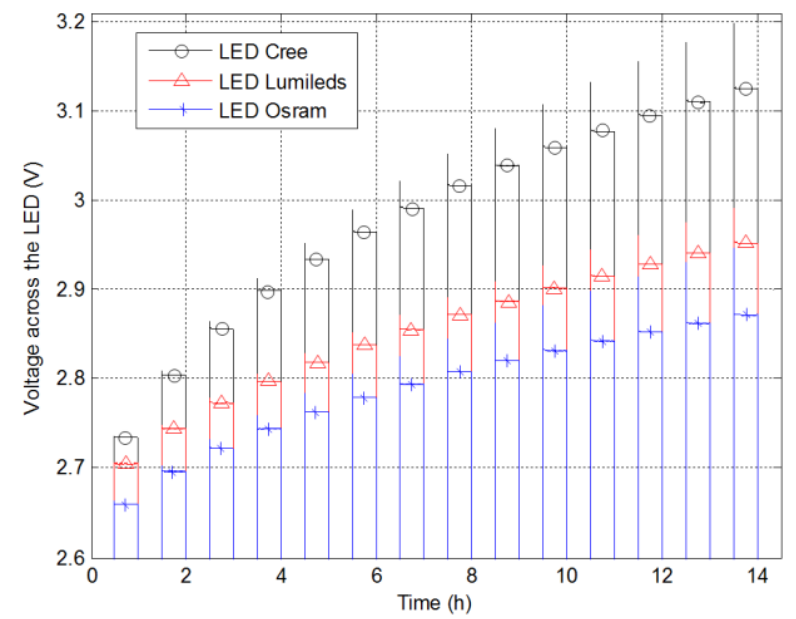

Fig. 8. Voltage across each LED for different forward currents

With the previous voltage measurements and a good estimation of $\mathrm{R}_{s p-h s}$, it is possible to predict the temperature of the solder point by using equation (3).

The measured and modelled rise of LED solder point temperature is illustrated in Fig. 9. Only one temperature evolution has been plotted for LEDs from Cree and Lumileds because they have exactly the same temperature during all the experiment.

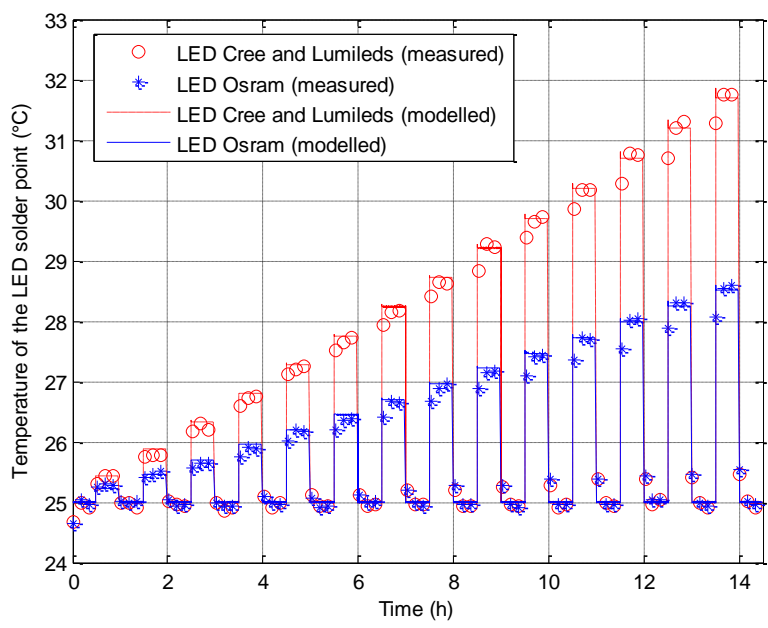

Fig. 9. Evolution of LED solder point temperatures 
The temperature of the Osram LED is very low compared to the other LEDs. To have a model which well fits with data, an abnormal very low $\eta_{\text {heat }}$ has been computed $\left(\eta_{\text {heat }}=0.45\right)$.

To evaluate the junction temperature of the LED, there is a relation between the junction temperature and the solder point of an LED, defined as:

$$
\mathrm{T}_{j}=\mathrm{T}_{s p}+\mathrm{R}_{j-s p} \mathrm{P}_{\text {heat }}
$$

where

$\mathrm{T}_{j}$ is the junction temperature of the $\operatorname{LED}\left({ }^{\circ} \mathrm{C}\right)$

$\mathrm{R}_{j-s p}$ is the thermal resistance of the LED between junction and solder point $\left({ }^{\circ} \mathrm{C} / \mathrm{W}\right)$

Due to LED heating, according to our experiments, a drop of luminous flux occurs for every assessed current and can be limited to maximum $10 \%$ if the junction temperature stays below $80^{\circ} \mathrm{C}$. In this case, the drop of luminous flux can be neglected because it is not visible for the common human eye [27]. As a consequence, it has been chosen to discard the results given by the Pareto optimization if the junction temperature is higher than $80^{\circ} \mathrm{C}$. The same observation has been made concerning the drop of voltage across a heating LED, phenomenon which is also neglected because it does not have a significant impact on the LED junction temperature prediction.

The next section presents how to estimate the ageing of a LED in function of its junction temperature.

\section{LED AGEING MODEL}

The study of LED ageing, also called lumen maintenance, is determined by its lumen depreciation. The lifetime of an LED is defined by the number of operating hours before the luminous flux decreases below $70 \%$ of its initial value. This lifetime is often noted L70. According to the Illuminating Engineering Society of North America (IESNA), the standard TM 21 provides a method to assess the lumen maintenance of LEDs.

A simplified model of lifetime has been computed based on [27] as illustrated in Fig 10. In this model, it is assumed that the ageing of the LED is related to the junction temperature. For warmer junction temperatures, an LED operates less hours. Furthermore, two forward currents have been represented because the lifetime also depends on this parameter. As it is a simplified model, it will be considered that currents below $350 \mathrm{~mA}$ have the $350 \mathrm{~mA}$ behaviour, whereas higher currents will follow the $700 \mathrm{~mA}$ ageing model.

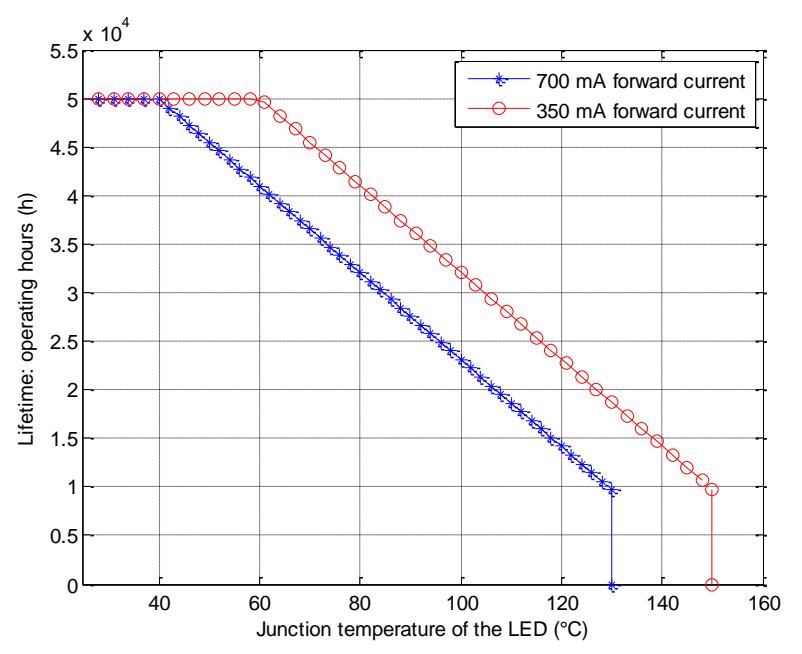

Fig. 10. Simplified lifetime model of an LED [26]

It is important to define an equivalent period depending on the junction temperature: for example in Fig. 10, the LED can operate up to 50,000 hours for a junction temperature of $40^{\circ} \mathrm{C}$ but it can only operate 10,000 hours if the forward current is $700 \mathrm{~mA}$ and the junction temperature is $120^{\circ} \mathrm{C}$. A simple way to take this into account is to consider that the LED is working 5 times more at $120^{\circ} \mathrm{C}$ than at $40^{\circ} \mathrm{C}$. Considering a factor noted $\alpha$ enables to count the equivalent operating hours of LEDs for different junction temperatures and forward currents:

$$
\alpha=\frac{t_{o p}\left(25^{\circ} C, \mathrm{I}_{\mathrm{f}}\right)}{\text { Lifetime }\left(\mathrm{T}_{j L E D}, \mathrm{I}_{\mathrm{f}}\right)}
$$

where

$t_{o p}\left(25^{\circ} \mathrm{C}, \mathrm{I}_{\mathrm{f}}\right)$ is the operating lifetime of an LED at $25^{\circ} \mathrm{C}$ for a given current (hours)

Lifetime $\left(\mathrm{T}_{j L E D}, \mathrm{I}_{\mathrm{f}}\right)$ is the number of hours given by the LED lifetime model for given junction temperatures and currents (hours), as described in Fig. 11.

As defined earlier, the lighting mission profile is close to a shopping center: 12 hours a day, 6 days per week and 52 weeks per year, it represents 74880 hours of lighting over 20 years. The number of replacements over 20 years, noted $\mathrm{N}_{\text {repl }}$ can be calculated:

$$
\mathrm{N}_{\text {repl }}=\frac{\alpha \times T_{O N}}{t_{o p}\left(25^{\circ} \mathrm{C}, \mathrm{I}_{\mathrm{f}}\right)}
$$

with

$T_{O N}$ the number of operating hours over 20 years (hours)

Once luminous, thermal and ageing behaviour of LED have been discussed, the cost analysis of the luminaire needs to be developed. This model and the results of the methodology will be given in the next section. 


\section{VI.} THE METHOD

The cost analysis of the LED luminaire will be done over a period of 20 years. Assuming that the power converter associated to each luminaire configuration have roughly the same price, this cost will not be taken into account in the model because it will have no influence on the final comparison. In order to evaluate more solutions, three different heatsinks will be assessed for each forward current. As illustrated in Fig. 5, the luminaire will need a power supply comprised between $20 \mathrm{~W}$ and $60 \mathrm{~W}$ so heatsinks with a thermal resistance of $0.4 \mathrm{~K} / \mathrm{W}, 1.2 \mathrm{~K} / \mathrm{W}$ and $2 \mathrm{~K} / \mathrm{W}$ have been selected. An additional cost per LED has been computed respectively corresponding to $0.6 €, 0.35 €$ and $0.2 €$. This cost is based on the cost of large heatsinks ( $200 \times 200 \times 25 \mathrm{~mm})$.

The following formula is often used in renewable power projects like in $[28,29]$ and well-known under the name of levelized cost of energy. It has been adapted to lighting systems for this study in order to calculate the luminaire annualized cost $L A C$ (€/operating hour):

$$
L A C=\frac{\left(C_{\text {Lighting }}+C_{\text {repl }}\right) F+C_{O \& M}}{T_{\text {ON yearly }}}
$$

with

$C_{\text {Lighting }}$ the initial capital cost of the luminaire corresponding to the cost of LEDs and heatsink $(€)$

$C_{\text {repl }}$ the replacement cost of LEDs over 20 years $(€)$

$C_{O \& M}$ the annual cost of maintenance $(€)$, consider $50 €$ per luminaire

$T_{\text {ON yearly }}$ the number of operating hours per year (hours)

$F$ the capital recovery factor, $F=0.0802$ for this project. It is defined as in [28 - 30]:

$$
F=\frac{i_{a}\left(1+i_{a}\right)^{x}}{\left(1+i_{a}\right)^{x}-1}
$$

where

$i_{a}$ is the discount rate, considered equal to $5 \%$ for a project of 20 years

$x$ is the duration of the project (years)

The LED model is now completed. It is possible to evaluate each LED luminaire configuration over 20 years of operation subject to its annualized cost and energy consumption as described in Fig. 2.

Three Pareto fronts are obtained, as illustrated in Fig. 11. In Fig. 11, D1, D2 and D3 designate respectively heatsinks with thermal resistance of $0.4 \mathrm{~K} / \mathrm{W}, 1.2 \mathrm{~K} / \mathrm{W}$ and $2 \mathrm{~K} / \mathrm{W}$.

It is to notice that for each type of LED, an inversion occurs which means that the heatsink which leads to the optimal luminaire for low power does not lead to the optimal luminaire for high power. This inversion occurs when the lifetime model switches from the $350 \mathrm{~mA}$ ageing curve to the $700 \mathrm{~mA}$ curve.

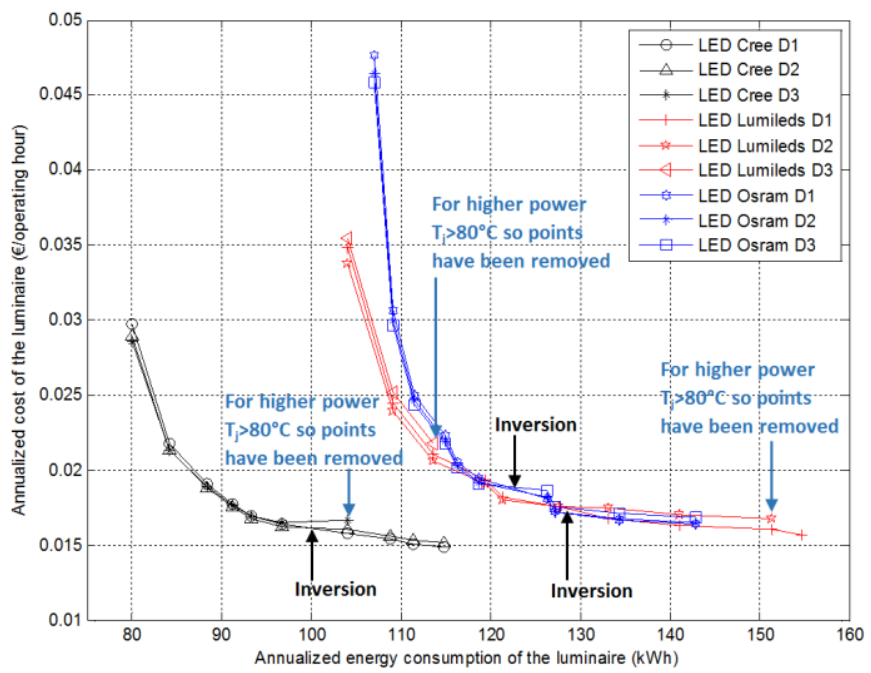

Fig. 11. Annualized cost vs. power of the luminaire

Some points have been removed from the Fig. 11 because the junction temperature of the LED reached $80^{\circ} \mathrm{C}$ which means that the luminous flux will decrease over $10 \%$ from its nominal value: these solutions are not acceptable. Currents below $50 \mathrm{~mA}$ have also been removed because these configurations are not optimal: they lead to an expensive annualized cost and an annualized energy consumption which is greater than the energy consumption induced by the $50 \mathrm{~mA}$ or $100 \mathrm{~mA}$ forward currents configurations.

Forward currents from $50 \mathrm{~mA}$ to $700 \mathrm{~mA}$ are optimal in Pareto sense. For higher currents, the annualized cost of the luminaire is cheaper because the number of LEDs is smaller but the annualized energy consumption is bigger. The final user has to make a trade-off between buying a cheaper luminaire or making energy consumption savings. Some heatsinks lead to more optimal solutions but care should be taken with these results because this methodology is very sensitive to the ageing model of the LED. In other words, the LED ageing model needs to be very accurate to avoid any misleading interpretation.

\section{CONCLUSION}

A methodology to find the optimal forward current of an LED luminaire has been proposed. It takes into account the luminous efficacy, the junction temperature modeling, the lifetime prediction and different costs associated to a LED luminaire.

Even if this method is very sensitive to the lifetime model, it appears that, for the three tested and simulated LEDs with different heatsinks, forward currents between $50 \mathrm{~mA}$ and $700 \mathrm{~mA}$ lead to optimal combinations of annualized cost and annualized energy consumption of the luminaire.

Due to the modularity of this methodology, LED models used in this method can be improved or adapted to any type of 
LEDs. Other models may be added to improve the relevance of this methodology: reliability of the LED configuration (string, series string, series-parallel string modules), life cycle assessment (LCA), impact of current waveform on the behaviour of LEDs, design of DC/DC converters...

\section{ACKNOWLEDGMENT}

This work was partially supported by the NeOCampus project from the Université de Toulouse, Toulouse III Paul Sabatier, France.

\section{REFERENCES}

[1] International Energy Agency (IEA), "Light's Labour's lost: Policies for Energy-efficient Lighting", Paris 2006, ISBN: 926410951X

[2] International Energy Agency (IEA), Key World Energy STATISTICS 2015, Paris 2015.

[3] Colin J. Humphreys, Solid-State Lighting, MRS Bulletin, Volume 33, Issue 04, avril 2008, pp 459-470.

[4] U.S. Department of Energy, "Life-Cycle Assessment of Energy and Environmental Impacts of LED Lighting Products - Part I: Review of the Life-Cycle Energy Consumption of Incandescent, Compact Fluorescent, and LED Lamps", technical report, february 2012 updated august 2012.

[5] Thermal Management Considerations for SuperFlux LEDs, application brief AB20-4, LUMILEDS.

[6] L. Trevisanello, M. Meneghini, G. Mura, M. Vanzi, M. Pavesi, G. Meneghesso, and E. Zanoni, "Accelerated Life Test of High Brightness Light Emitting Diodes”, IEEE Trans. Device Mater. Rel., vol. 8, no. 2, pp. 304-311, Jun. 2008.

[7] S. Y. (Ron) Hui, Y. X. Qin, "A general Photo-Electro-Thermal Theory for Light Emitting Diode (LED) systems", IEEE Transactions on Power Electronics, vol. 24, no. 8, pp. 1967-1976, august 2009.

[8] J. M. Zhou and W. Yan, "Experimental investigation on the performance characteristics of white LEDs used in illumination application", in Proc. PESC2007, Orlando, FL, Jun., pp. 1436-1440.

[9] S. Buso, G. Spiazzi, M. Meneghini, and G. Meneghesso, "Performance Degradation of High-Brightness Light Emitting Diodes under DC and pulsed bias”, IEEE Trans. Device Mater. Rel., vol. 8, no. 2, pp. 312-322, June 2008.

[10] M. Arik, C. Becker, S.Weaver, and J. Petroski, "Thermal management of LEDs: Package to system", Proc. SPIE, vol. 5187, pp. 64-75, 2004.

[11] Ray-Lee Lin, Jhong-Yan Tsai, Shun-Yao Liu, Hsin-Wei Chiang, "Optimal Design of LED Array Combinations for CCM Single-Loop Control LED Drivers", IEEE Journal of Emerging and Selected Topics in Power Electronics, Vol. 3, No. 3, September 2015, pp. 609-616.

[12] M. Nishikawa, Y. Ishizuka, H. Matsuo, and K. Shigematsu, "An LED drive circuit with constant-output-current control and constantluminance control," in Proc. Telecommun. Energy Conf. (INTELEC 2006), Sep., pp. 1-6.

[13] B. Ackermann, V. Schulz, C. Martiny, A. Hilgers, and X. Zhu, "Control of LEDs," in Proc. IEEE IAS 2006, Oct., pp. 2608-2615.

[14] Pedro S. Almeida, Fernando J. Nogueira, Luiz F. A. Guedes, Henrique A. C. Braga, "An experimental study on the photometrical impacts of several current waveforms on power white leds", XI Brazilian Power Electronics Conference, pp. 728 - 733, 11-15 Sept. 2011.

[15] Arnold Wilkins, Jennifer Veitch, Brad Lehman, "LED Lighting Flicker and Potential Health Concerns: IEEE Standard PAR1789 Update", IEEE Energy Conversion Congress and Exposition, 12-16 Sept. 2010, pp. $171-178$.

[16] IEEE standard 1789-2015, "IEEE Recommended Practices for Modulating Current in High-Brightness LEDs for Mitigating Health Risks to Viewers".

[17] Christophe Martinsons, Georges Zissis, "Potential Health Issues of Solid-State Lighting", IEA 4E final report, 24 September 2014.

[18] R. Banos, F. Manzano-Agugliaro, F.G. Montoya, C. Gil, A. Alcayde, J. Gomez, "Optimization methods applied to renewable and sustainable energy: A review", Renewable and Sustainable Energy Reviews (2011) 1753-1766.
[19] Ning Xiong, Daniel Molina, Miguel Leon Ortiz \& Francisco Herrera, "A walk into Metaheuristics for Engineering Optimization: Principles, Methods and Recent Trends", international journal of computational intelligence systems, vol. 8 issue 4, pages 606-636, July 2015.

[20] Pedro S. Almeida, Joao M. Jorge, Claudio R.B.S. Rodrigues, Guilherme M. Soares, "A Novel Method of Current Equalization in LED Strings Based on Simple Linear Circuit", IEEE International Symposium on Industrial Electronics, June 2011, pp. 95 - 100.

[21] Datasheet, Cree XLamp XT-E LEDs, CLD-DS41 rev 14 [Online]. Available: http://www.cree.com/ /media/Files/Cree/LED-Componentsand-Modules/XLamp/Data-and-Binning/XLampXTE.pdf

[22] Datasheet, DS107 LUXEON Rebel PLUS Product Datasheet 2015 [Online]. Available: http://www.lumileds.com/uploads/380/DS107-pdf

[23] Datasheet, OSLON Square Datasheet Version 1.2 GW CSSRM1.CC [Online]. Available: http://www.osramos.com/Graphics/XPic4/00199140_0.pdf/GW\%20CSSRM1.CC\%20\%20 OSLON\%20 Square\%20(EnglishDeutsch).pdf

[24] E. Fred Schubert, Light-Emitting Diodes, second edition, Cambridge University Press, july 2006, pp.59-112.

[25] Andras Poppe, "Multi-domain compact modeling of LEDs: An overview of models and experimental data", Microelectronics Journal, Volume 46 Issue 12, December 2015, pp. 1138-1151.

[26] Yaxiao Qin, Deyan Lin, S. Y. (Ron) Hui,“A simple method for comparative study on the thermal performance of leds and fluorescent lamps", IEEE Transactions on Power Electronics, vol. 24, no. 7, pp. 1811-1818, July 2009.

[27] U.S. Department of Energy, "LED Measurement Series: LED Luminaire Reliability", PNNL-SA-61137, October 2009.

[28] R. Luna-Rubio, M. Trejo-Perea, D. Vargas-Vazquez, G.J. Rios-Moreno, "Optimal sizing of renewable hybrids energy systems: A review of methodologies", Solar Energy 86 (2012) 1077-1088.

[29] Yang Hongxing, Zhou Wei, Lou Chengshi, "Optimal design and technoeconomic analysis of a hybrid solar - wind power generation system", Applied Energy 86 (2009) 163-169.

[30] Donald S. Remer, Armando P. Nieto, "A compendium and comparison of 25 project evaluation techniques. Part I: Net present value and rate of return method", Int J. Production Economics 42 (1995), 79-96. 